\title{
Experimental Researches on the Behavior of Polypropylene Pipes at the Physical-mechanical Testing
}

\author{
ELENA VALENTINA STOIAN ${ }^{1}$, MARIA CRISTIANA ENESCU ${ }^{1 *}$, \\ IVONA CAMELIA PETRE ${ }^{1 *}$, RUXANDRA ELENA BRATU ${ }^{2}$, VASILE BRATU ${ }^{1}$, \\ CARMEN OTILIA RUSANESCU ${ }^{3}$ \\ ${ }^{1}$ Valahia University of Targoviste, Faculty of Materials Engineering and Mechanics, 13 Sinaia Alley, 130004, Targoviste, \\ Romania \\ ${ }^{2}$ Politehnica University of Bucharest, Faculty of Materials Science and Engineering, Romania, 313 Splaiul Independentei, \\ 060042, Bucharest, Romania \\ ${ }^{3}$ Politehnica University of Bucharest, Faculty of Engineering of Biotechnical Systems, Romania, 313 Splaiul Independentei, \\ 060042, Bucharest, Romania
}

\begin{abstract}
Lately, PP-R pipes have become increasingly popular in terms of drinking water installations and heating. Comparated to the classic pipes from copper or steel, pipes from propylene are much easier to use, they have obvious qualities and they are marketed at a much lower price. The study aims a comparative analysis of the physical-mechanical properties of the four most common types of pipes from propylene, which are currently found in commerce : simple without insertion $(P P-R)$, with insert of composite fiber $(P P-R-C F)$, with insert of basalt fiber $(P P-R-B F)$ and with insert of aluminium (PP-R$A I F)$. Experimental research showed that from the point of view of thermal expansion, the best behavior is from the pipes from propylene without any insert and the value of the thermal expansion coefficient for the reinforcement pipe with basaltic fiber is very small. After these attempts at tensile, it resulted that all four samples which were analyzed from the point of view of the tensile strength, don't exceed the limit that was given by the manufacturer (10-30 MPa), the values obtained being: for pipe from polypropylene of $17 \mathrm{MPa}$, for pipe from polypropylene with insert of aluminium of $18 \mathrm{MPa}$, for the test tube from pipe of polypropylene with insert of basalt fiber of $29 \mathrm{MPa}$ and for the test tube from pipe of polypropylene with insert of composite fiber of $30 \mathrm{MPa}$. Therefore, from the point of view of the behavior at tensile and bending, the best behavior is from the pipes from polypropylene with insert of basalt fiber and pipes from polypropylene with insert of composite fiber.
\end{abstract}

Keywords: polypropylene, reinforcement polypropylene, thermal expansion, tensile, bending

\section{Introduction}

The economic-industrial competitiveness will always impose ways on how to obtain your products, with high technical parameters, to which the functional characteristics are combined with complete exploitation of materials properties. This can be realized by using high generation materials, with a better machinability and made through new or improved technologies, adapted to the new needs of humanity.

In this context are also included new materials, generically called "second generation materials" (including composite materials, minerale ones, ceramical and syntetized), this already have found a large utilization on different areas, from which we can mention: in construction of technological equipament and machine tools, in electronics and electrotechnics, in the aerospace field, in naval transport, in the rolling stock industry, in car industry and energy equipment etc.

Since the oldest times, people have accomplished composite materials of what the nature has given them, from which we remember: the brick (made of mud and straw), security fences ( made of twigs and earth) and more recently reinforcement concrete (cement, gravel and iron). Also, the natura is offering us models of composite materials: bones, muscles, bamboo, wood, etc. [1-5]

Composite materials are included in the category of compound materials, which were called not long ago consolidated plastic materials.

*email: cristiana_enescu@yahoo.com,petreivonacamelia@yahoo.com 
Pipes made of polypropylene, also called PPR pipes, have become increasingly used in the field of drinking water installations and heating for household and industrial use. Making a comparison with the classic pipes used in installations made of copper or steel, the ones which are made of polypropylene are much easier to handled, they have obvious better qualities being sold at a much lower price than the others, imposing themselves on the profile market, being appreciated by clients but also by professionals [5-8].

The tests performed by the manufacturers had revealed the fact that these pipes made of polypropylene can be used in systems and installations that use fluids with temperatures between -20 and $+95^{\circ} \mathrm{C}$, working pressures of maximum 20 bar, have a high resistance to chemical corrosion and last but not least they can be mounted in direct contact with the building materials, didn't need necessarily their protection with different types of insulation.[9-13]. For installations which are executed on the outside must be used, though, insulation elements and protection, because direct exposure to ultraviolet rays of poypropylene pipes will be able to produce their degradation, by decomposing polymers from the outer layer of the pipe, generating a process of grinding the pipe material [14-18].

\section{Materials and methods}

The analyzes are realized on four types of pipes, from different materials, which will have the following acronyms used in the text, such us: PP-R (polypropylene without insertion), PP-R-CF (reinforcement polypropylene with composite fiber), PP-R-BF (reinforcement polypropylene with basalt fiber), PP-R-AIF (reinforcement polypropylene with aluminium fiber). All the pipes used in this study have had the same diameter of $\varnothing 20 \mathrm{~mm}$.

Polypropylene lend themself with succes at the construction of the hot water pipes which are intended for continuous functioning at a temperature of $180 \mathrm{~F}$, with a pressure depending on the thickness and type of the wall that pipe has. The pipes can be build with reinforcement layers to increase specific properties such us decrease expansion / longitudinal thermal contraction, which makes them suitable for important aplications, such us pressure pipes (sanitary facilities, hydraulic) in the high commercial buildings.

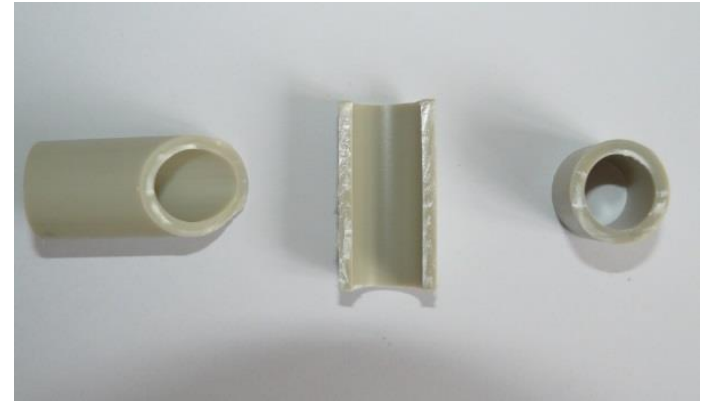

Figure 1. PP-R pipe without insertion

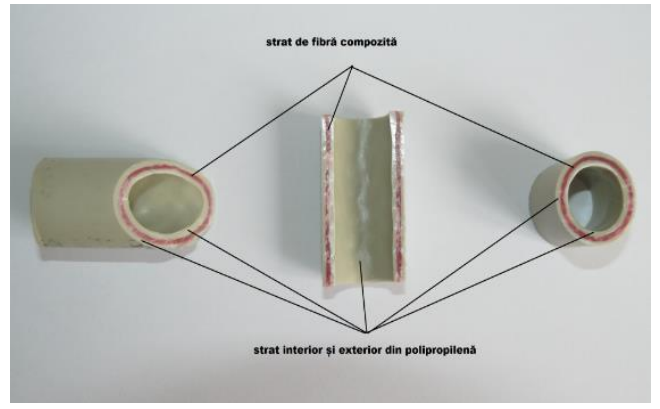

Figure 2. Arrangement of the three layers at the PP-R-CF pipe

This type of pipe (Figure 1) doesn't have any type of insert, being used especially in cold water installations, having the biggest thermal expansion coefficient, according to the graph in Figure 6.

The PP-R pipe reinforcement with composite fiber (Figure 2) is considered to be the most performance version in the entire range of polypropylene. In the figure can be distinguished the three layers from which the pipe is formed and namely: polypropylene-composite fiber-polypropylene. The color of the composite fiber is personalized by every manufacturer. The composite fiber layer provides a lower coefficient of thermal expansion, according to Figure 7. 


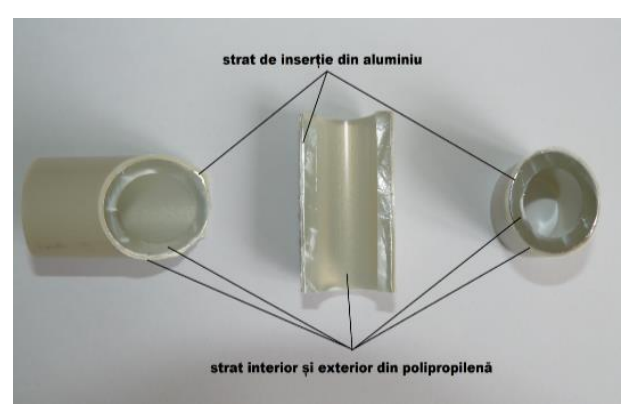

Figure 3. Arrangement of the three layers at the PP-R -AlF pipe

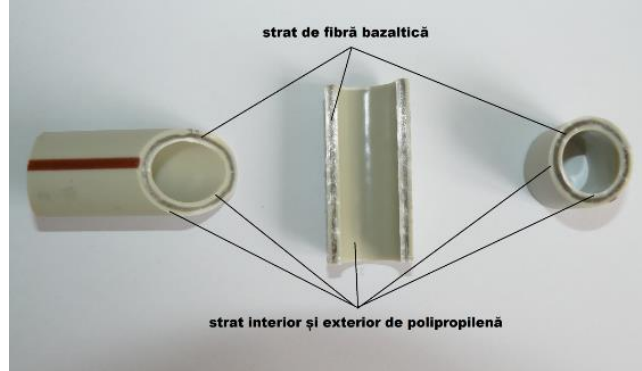

Figure 4. Arrangement of the three layers at the PP-R -BF pipe

The pipe PP-R-AIF with aluminium insert (Figure 3), as well as the reinforcement one with composite fiber, is made of three layers: the outer and inner layers are made of polypropylene, and in the middle we have a layer represented by an aluminium foil. This foil is wrapped, combined and then glued to polypropylene support with the help of a special film, also made of polypropylene.

As well as the reinforcement pipe of polypropylene with carbon fibers, the reinforcements ones with basaltic fiber (Figure 4) are new generation of appearances, they are coming with a update that must be taken into account, namely that the value of the coefficient of the thermal expansion is very small, even smaller than the coefficient of the reinforcement pipes with composite fiber and the ones with insert of aluminium.

The most important characteristics of pipes made of polypropylene are: high resistence to pressure and high temperatures. For example, the polypropylene pipe with insert of aluminium has a bigger conductivity than that pipe with insert of carbon. The maximum temperature that pipe can bear is $90^{\circ} \mathrm{C}$, and the nominal pressure is 20 bar [18-22].

Compared with the classic pipes from copper or steel, PP-R pipes with insert of composite have a much lower thermal expansion, especially the ones with basalt fiber. The pipes embedded in different materials, are constantly under pressure from all directions, demonstrating themselves high strength. The expansion is reduced up to $75 \%$ comparated to other pipes made of classical materials, the danger of the cracks in the pipe being almost eliminated.

a)

b)

c)

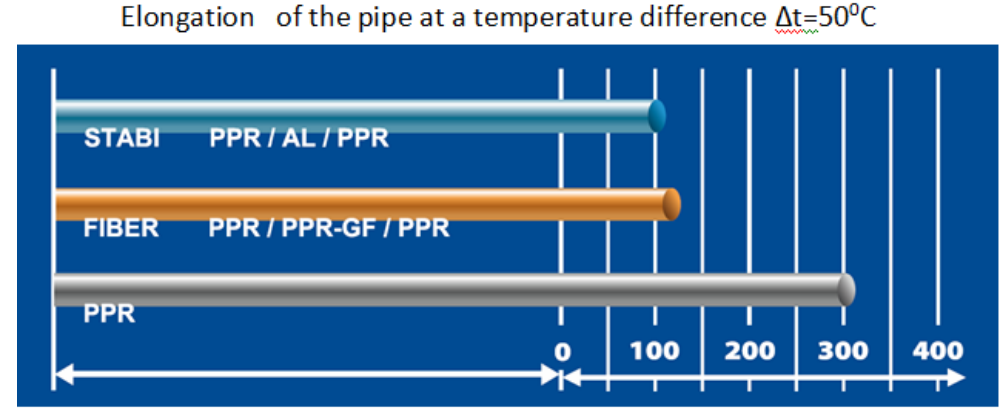

Pipe length $\mathrm{L}=50 \mathrm{~mm}$

Elongation $\Delta \mathrm{l}[\mathrm{mm}]$

Figure 5. Comparison between linear expansions of PP-R pipes with different inserts a)pipe with insert of aluminium;b) pipe with insert of fiberglass (composite fiber); c) PP-R simple pipe without insertion

Another important characteristic of polypropylene is the resistance to abrasion and heat. At the same time we must not forget outstanding dielectric and insulation qualities, as well as the resistance to repeated folding. From the point of view of the fragility, the polypropylene is less fragile than high density polyethylene and less flexible than low density polyethylene [19, 22, 23].

Polypropylene is a very stable polymer in aggressive chemical environments. At temperatures above $160-170^{\circ} \mathrm{C}$, it becomes soft compared to polyethylene, but it has a higher breaking streng. 
To define the minimum requirements for the evaluation of PP-RCT material performance, at the request of hydrostatic pressure, the reference curves were deducted from the long-term evaluation of the Beta-PPR RA7050 behavior according to ISO 9080. These reference curves form the basis for pipe design and are described by the following equation:

$$
\lg \mathrm{t}=\mathrm{A}+\frac{\mathrm{B}}{\mathrm{T}} \cdot \lg \sigma+\frac{\mathrm{C}}{\mathrm{T}}+\mathrm{D} \cdot \lg \sigma
$$

where:

$\sigma-$ the stress on the circumference(circular request) [MPa];

$\mathrm{T}$ - temperature $\left[{ }^{0} \mathrm{~K}\right]$;

$\mathrm{t}$ - time $[\mathrm{h}]$

$\mathrm{A}=119,546$;

$\mathrm{B}=23738,797$;

$\mathrm{C}=52176,696$;

$\mathrm{D}=31,279$.

The results obtained by using formula (1) are presented in figure 6 .

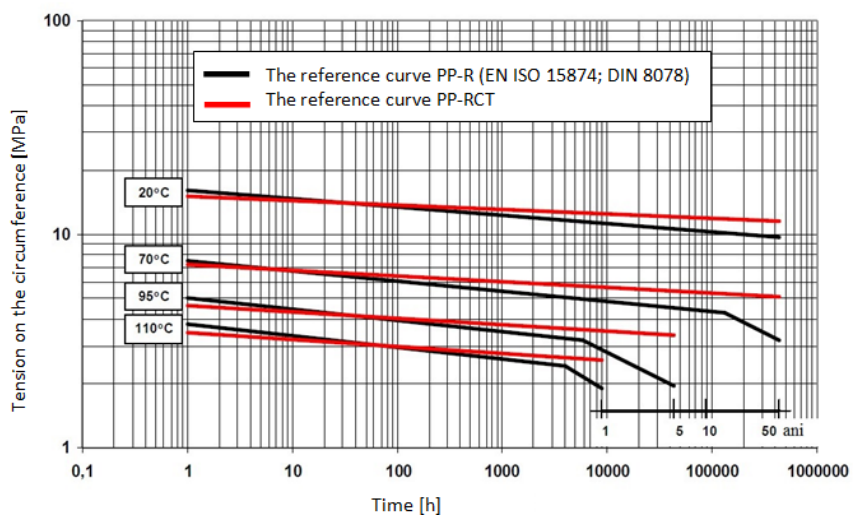

Figure 6. The comparison of the reference curves for PP-R and PP-RCT.

The curves define the hydrostatic pressure of the analyzed materials

The equation (1) is valid for the temperature range from 10 to $110^{0} \mathrm{C}(230 \mathrm{~F})$ and the graphic representation of the reference curves is shown in Figure 6, which also includes the comparison with the standard PP-R material. This graph clearly illustrates the long-term resistance of PP-RCT compared to the standard PP-R.

Increasing the long-term reliability of PP-RCT material lead to the possibility of reducing the outer dimensions of the pipes used for sanitary facilities and heating.

Therefore, PP-RCT pipes can resist to pressure of function much higher than pipes of the same size made of PP-R.

\section{Results and discussions}

The presentation aims to analyze the behavior of the four types of PP-R pipes mentioned, to physicomechanical stresses, such as thermal expansion, tensile and bending, knowing that, before breaking, the values obtained for the simple tensile or repeated tensile cycles (loading - unloading), deformations (elongations) and necking, depend on the following factors: the type of pipe (with and without insertion material and its nature), the time of action of the force, the speed of loading; number of cycles and temperature in the piece.

\subsection{Determinations of thermal expansion}

PP-R is a material intended for pipe systems that operate at pressure and at high temperatures.

Determinations of thermal expansion were carried out in real conditions of operating of a existing heating installations, in which PP-R pipes are component parts. Various scenarios in which were 
stimulated the conditions necessary for the study were created. As observation and measurement devices, a digital camera, respectively a digital thermometer with infrared measurement, laser guidance beam and a callipers with rod for measuring depths, were used.

The determinations were made on sections of PP-R pipe, having a length of 4 meters and at different temperatures of the thermal agent, as follows: the initial length of the pipe (which is 4 meters) was measured at ambient temperature (approximately $30^{\circ} \mathrm{C}$ ); progressive the temperature of the heat agent has been raised from 10 to 10 degrees Celsius, starting at $30^{\circ} \mathrm{C}$ to $80^{\circ} \mathrm{C}$; at each temperature $(30,40,50$, $60,70$ and 80$)^{\circ} \mathrm{C}$, respectively the temperature difference $\Delta \mathrm{T}\left(10,20,30,40,50^{\circ} \mathrm{C}\right)$ measurements were made of the elongation of the pipe section in discussion; the results of the measurements were noted in Table 1, and then interpreted graphically, in Figure 7.

Tabel 1. Centralisation of the elongations of the analyzed pipes

\begin{tabular}{|c|c|c|c|c|c|}
\hline $\begin{array}{c}\text { Number of } \\
\text { determination }\end{array}$ & $\begin{array}{c}\text { Temperature } \\
\Delta \mathrm{T}\left[{ }^{0} \mathrm{C}\right]\end{array}$ & $\begin{array}{c}\text { Elongation PP-R- } \\
\mathrm{CF} \\
{[\mathrm{mm}]}\end{array}$ & $\begin{array}{c}\text { Elongation PP-R- } \\
\text { AlF } \\
{[\mathrm{mm}]}\end{array}$ & $\begin{array}{c}\text { Elongation PP-R- } \\
\text { BF } \\
{[\mathrm{mm}]}\end{array}$ & $\begin{array}{c}\text { Elongation PP-R } \\
{[\mathrm{mm}]}\end{array}$ \\
\hline 1 & 0 & 0 & 0 & 0 & 0 \\
\hline 2 & 10 & 2 & 1,5 & 1 & 3.5 \\
\hline 3 & 20 & 3,5 & 2,5 & 1.5 & 7 \\
\hline 4 & 30 & 5 & 4 & 2 & 10.5 \\
\hline 5 & 40 & 7 & 5 & 2.5 & 15 \\
\hline 6 & 50 & 9 & 6 & 3 & 18 \\
\hline
\end{tabular}



Figure 7. Graphic interpretation of the elongation of the analyzed pipes

The determinations followed the way of behaving at thermal expansion of simple polypropylene and those with different inserts used in the realisation of the systems and water and heating installations.

The data presented in Table 1 show that the elongation of the measured pipe sections behaved differently according to the characteristics of each type of pipe, the best behavior was at the simple polypropylene pipe without reinforcement, and the weakest being the pipe with basaltic insert .

\subsection{Determination of tensile strength}

Determinations of mechanical properties following bending and tensile requests were carried out on the same types of test tubes mentioned above, within the Institute of Multidisciplinary Scientific and Technological Research of the University Valahia of Targoviste (ICSTM-UVT), where it is a static stretching test system using an MTS Bionix device (as shown in Figure 8). 



Figure 8. The attempt machine for mechanical properties

The distance between the supports of the device for the three-point bending is $24 \mathrm{~mm}$.

Various graphic results can be obtained (applied stress-force, arrow-stress, applied force-arrow, etc.). Importantly, for a material test tube with certain dimensional characteristics, the variation of the arrow (displacement) can be determined according to the maximum applied force and the maximum bending stress.

Both graphs (force-displacement and stress-displacement) shows a linear portion parallel to the abscisa, which corresponds to the distance traveled, in empty, from zero point until the roll of the force application device reaches the test tube. The second portion represents the curve force-displacement and stress-displacement.

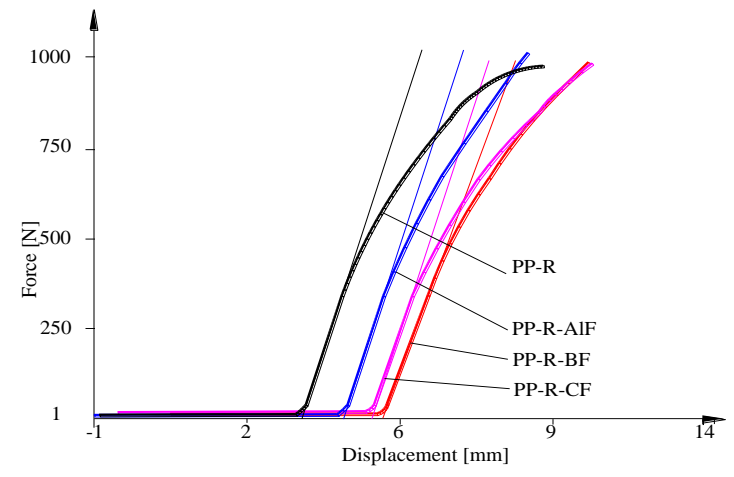

Figure 9. Force-displacement curve for the analysed test tubes

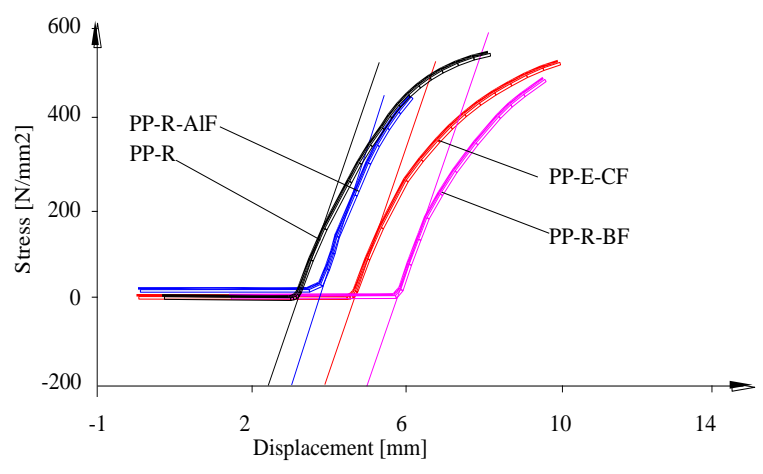

Figure 10. Stress-displacement curve for the analysed test tubes

From Figures 9 and 10, we can conclude that the polypropylene pipe without insertion behaves the worst from the point of view of bending, instead the pipe in the polypropylene with basaltic insert shows the best results from the point of view of bending test.

On the same test machine on which the incovation was carried out, the mechanical tensile properties of the $150 \times 20 \times 13.4 \mathrm{~mm}$ test tubes were also measured.

Figures 11 and 12 shows the results obtained for tensile testing of test tubes. 


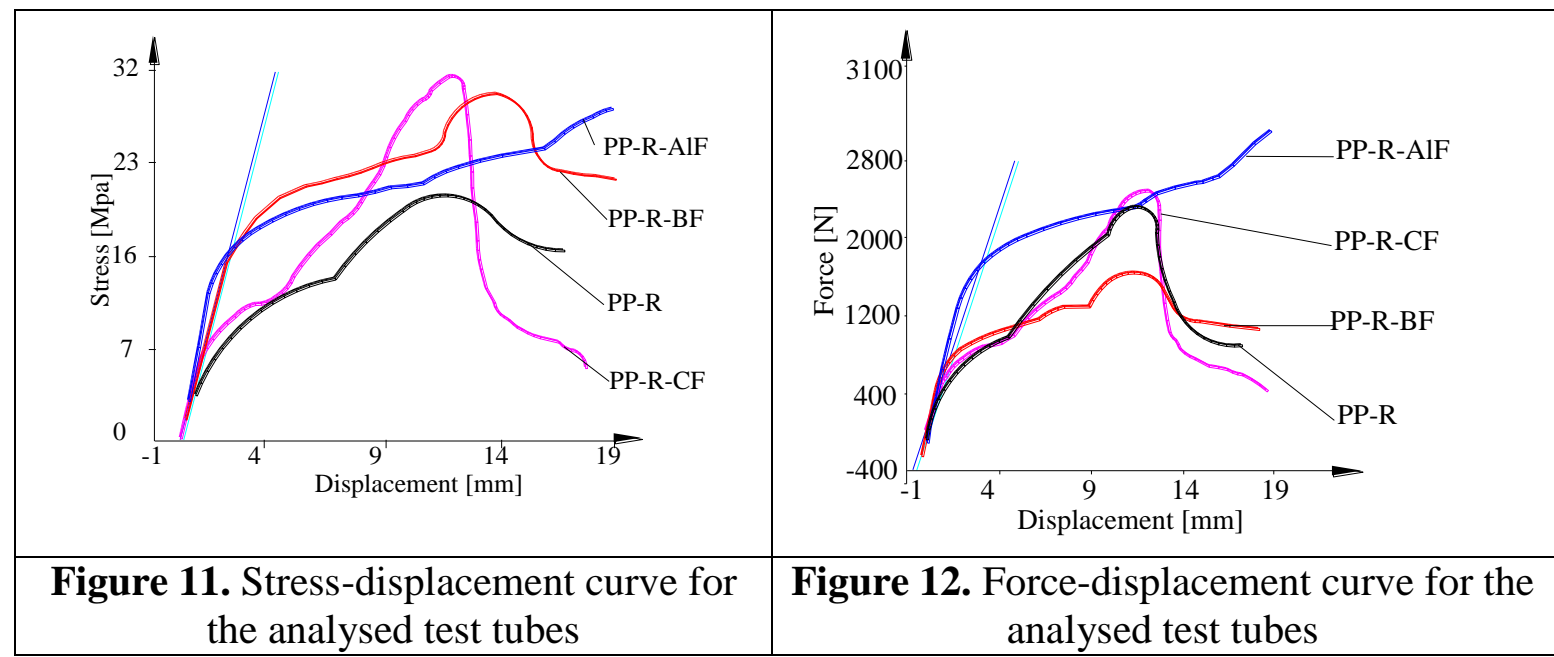

After all these attempts of tensile, it turned out that all the four samples analysed from the point of view of tensile strength do not exceed the limit given by the manufacturer $(10-32 \mathrm{MPa})$ the values obtained being: for the polypropylene pipe is $17 \mathrm{MPa}$, for the polypropylene pipe with aluminum insert the value is $18 \mathrm{MPa}$, for the polypropylene pipe test tube with basaltic fiber insert the value is $29 \mathrm{MPa}$, and for the polypropylene pipe test tube with composite fiber insert the value is $30 \mathrm{MPa}$.

\section{Conclusions}

From the determinations and measurements made in this presentation, where the thermal expansion and behavior to mechanical stress of polypropylene pipes were studied, it was aimed at highlighting the behavior of polypropylene in various forms so simple as well as with different inserts.

The data presented in Table 1 shows that the elongation of the measured pipe sections behaved differently according to the characteristics of each type of pipe, the best behavior was at the simple polypropylene pipe without reinforcement, and the weakest was the pipe with basaltic insert .

From the point of view of the testing at the bending, the polypropylene pipes with basaltic insert and composite fiber insert had the best behavior.

So from the point of view of tensile behavior, the polypropylene pipes with basaltic insert and composite fiber insert had the best behavior.

The values obtained for the test tubes described above are acceptable and fall within the average of the values given by the pipe manufacturer from PP-RCT.

From Table 1, as well as from graph 7, we can say that the use of composite materials in the reinforcement of polypropylene pipes, influences in a beneficial way their behavior in different situations and helps us to be able to choose in knowledge of the cause, suitable materials for the desired type of installation.

Studies carried out in this presentation can provide to the professionals information that they can use in the correct execution of an installation, regardless of its domestic or industrial nature.

The compact and uniform structure of the studied materials will prevent the formation of deposits of any kind on the walls. Therefore, the limestone $\left(\mathrm{CaCO}_{3}\right)$ from the water composition will not accede and implicit will not be able to deposit on the walls of the pipes. Phonic, this material is a good insulator reducing the noise made by the fluids that circulate through these pipes.

The use of PP-R pipes in installations makes the losses of heat to be small, from here resulting an important energy economy and implicit of money. The composite from inside the pipe does not allow a large exchange of temperature with the environment, regardless we are talking about air or concrete. Compared to copper or steel pipes, those in PPR have a better efficiency, having a very low thermal transfer coefficient. 
Polypropylene pipes have multiple uses in many fields of activity. Simple pipes without any kind of insertion are used successfully in drinking water supply systems and installations (not toxic and hygienic), irrigation systems, waste water collection, transport for natural gas, etc.

\section{References}

1.G. COMELEATA, C. ENESCU, M. ZAHARIA, Matériaux composites a matrice organique, vol. I, Ed. Printech, Bucuresti, 2006.

2.EUGEN GHITA, GILBERT RAINER GILLICH , ILARE BORDEAU, MIRCEA VODA, CATALIN TROI, Aspecte ale comportãrii polimerilor la solicitari de tractiune, Mater. Plast., 44 (2), 2007.

3.GHEORGHIU, H., HADAR, A., CONSTANTIN, N., Calculul structurilor din materiale izotrope si anizotrope, Editura Printech, Bucuresti, 1998, p. 59.

4.GILLICH, G.R., SAMOILESCU, G., BERINDE, F.C., CHIONCEL, C.P., Determinarea experimentala a caracteristicii de rigiditate si a modulului de elasticitate a cauciucului utilizâand reprezentarea timp-frecventă, Mater. Plas., 44 (1), 2007.

5.GHIOCA, P., BUZDUGAN, E., CINCU, C., IANCU LORENA., ZAHARIA, C., ZECHERU, TEODORA.,Compozite politeilenice antisoc, Mater.Plast., 44, (3), 2007, 175.

6.CARMEN OTILIA RUSANESCU, COSMIN JINESCU, MARIN RUSANESCU , MARIA CRISTIANA ENESCU, FLORINA VIOLETA ANGHELINA, ELENA VALENTINA STOIAN , VERONICA DESPA, Mathematical Modelling of the Stress-Strain Curve for 31VMn12 Ecological Steel, Mater.Plast., 54, (3), 2017,409.

7.RUSANESCU, C.O., RUSANESCU, M., ANGHELINA FL. V., Optoelectronics and advanced materials Rapid communications, 7, no.11-12, 2013, p. 947.

8.C.O.RUSANESCU, M. RUSANESCU, The stress-strain curves determined for microalloy steel with v determined on the torsion tests, Metalurgia (Bucharest) 59,1 2007, p. 38 ..

9.MARIA CRISTIANA ENESCU, SIMULATION DE RESISTENCE À LA TRACTION ET COMPRESSION DANS UN COMPOSITE MACROMOLÉCULAIRE, U.P.B. Sci. Bull., Series B, Vol. 72, 3, 2010.

10.ILEANA NICOLETA POPESCU, ADRIAN CATANGIU, ELENA VALENTINA STOIAN, DAN NICOLAE UNGUREANU, Îndrumar de laborator, Materiale compozite, Valahia University Press Târgovişte 2014.

11.RUSANESCU, C.O., RUSANESCU, M., JINESCU, C., BIRIS, S.S.,Laser Hardening Influence of Metal Surfaces. Mater. Plast., 55(2), 2018, 184.

12.CORNELIU DRUGA, RADU NECULA, DIANA COTOROS, ROXANA MICLAUS, ANGELA REPANOVICI,SARAH ADRIANA NICA, Experimental Research Regarding the Thermomechanical Behaviour of PMMA During Recovery of Patients with Joint Replacements, Mater. Plast., 54(4), 2017. 13.HOESS A., LOPEZ A., ENGKVIST H., KARLSSON OTT M., PERSSON C., Materials Science and Engineering C, 62, Elsevier, 2016, p.274.

14.GOANTA, V., HADAR, A., LEITOIU, B., Mater. Plast., 47(4), 2010, 450.

15. DUARTE G. W., PELLEGRIN M. Z., JUNIOR J. F., SANTOS A.L.G., RIELLA H. G., FIORI M. A., J. Mat. Sci. Res., Vol. 3 (1), 2014, p. 94.

16.HOLDANG G., Thermoplastic Elastomers in Applied Plastics Engineering Handbook: Processing and Materials, Elsevier, Oxford UK, 2011, p. 77.

17.GEORG GUTT, SONIA GUTT, DORU DUMITRU PALADE, FRIEDRICH KLEIN, KARLHEINZ G. SCHMITT THOMAS, Testing and characterization of metallic materials, Technical Publishing House, Bucharest , 2000, p.180.

18.SRIVATSAN T.S., AL-HAJRI M., SMITH C., PETRAROLI M., The tensile response and fracture behavior of 2009 Al alloy metal matrix composite. Mater Sci.Eng A, 346, 2003, p.91.

19.DOEL TJA, LORETTO MH., BOWEN P. Mechanical properties of Al based particulate metalmatrix composites.Composites 24,1993, p.270. 
20.MCDANELS DL., Analysis of stress-strain, fracture and ductility behavior of Al matrix composites containing discontinuous silicon carbide reinforcement. Metall Trans A, 16A, 1985,p.1105.

21.TSAI TY., Polyethylene terephthalate-clay nanocomposites, editors Polymer-clay nanocomposites, New York: John Wiley \& Sons; 2000. p.173.

22.MARIA CRISTIANA ENESCU, ELENA VALENTINA STOIAN, ALEXIS NEGREA, SIMONA MIHAI, IVONA PETRE, CARMEN OTILIA RUSANESCU, Experimental and Virtual Studies in Mechanical Applications of PP-RCT Pipes with Armored Materials, Mater. Plast., 56(2), 2019, 324.

23.RAMSTEINER F., T.ARMBRUST, Fatigue crack growth in polymers, Elsevier LTd. Polymer Testing 20, 2001, p.321.

Manuscript received: 25.03 .2020 